\title{
Possibility of inducing glandular stomach cancer in rats exposed to asbestos
}

\author{
F M KOGAN, N N VANCHUGOVA, V N FRASCH \\ From the Research Institute of Labour Hygiene and Professional Disease, 620014 Sverdlovsk, USSR
}

ABSTRACT The possibility of glandular stomach cancer being induced was studied in 75 random阿 bred white rats exposed to chrysotile asbestos. A perforated polyethylene capsule containing $100 \mathrm{mg}$ asbestos and filler (beef fat and natural wax mixture 1:1) was introduced in an artificial bag place节 on the greater curvature of the stomach. A capsule containing filler only was introduced in a similar way in $\mathbf{4 0}$ control rats. In the following 25 months, 18 tumors of the stomach and abdominal cavity were found in the rats treated with asbestos (eight adenomas, two adenocarcinomas, one carcino: sarcoma, one forestomach cancer, one intestinal adenocarcinoma, two peritoneal mesotheliomas, and three abdominal lymphoreticulosarcomas.) Among the control rats no such tumors were found음 The results of the experiment are discussed in connection with epidemiological data on stomachcancer in asbestos workers.

An increased rate of stomach cancer in men occupationally exposed to asbestos has been reported in several epidemiological investigations. ${ }^{1-4}$ Similar assumptions are considered in respect of the action of asbestos in drinking water. ${ }^{56}$ Using the retrospective method we have shown that the incidence of cancer in men engaged in asbestos mining or industries is significantly higher than in the general population. ${ }^{7}$ Increased mortality from intestinal cancer has also been observed for those exposed to asbestos.

It is known, however, that despite their importance, epidemiological investigations cannot unambiguously trace aetiological factors. We believe that experiments on the direct action of asbestos on the stomach wall will confirm its role. Attempts to induce stomach cancer experimentally have been made solely by the ingestion of asbestos with food or water; negative results have been obtained in most studies $^{8-14}$ ( $R$ Truhaut, personal communication, 1982). The conclusions drawn were based on experiments with rats, hamsters, ${ }^{1014}$ and monkeys. ${ }^{9}$ Some of these investigations were performed on a large number of animals. Thus 1850 rats were used in one of the experiments by the National Institute of Environmental Health and Safety (USA) ${ }^{15} ; 5158$ rats in another experiment ${ }^{16}$; and 759 hamsters in the experiments of the National Toxicolgical Program ${ }^{13}$; whereas Truhaut used more than 1200 rats (personal communication). At the same time the few

Accepted 13 October 1986 investigations in which the ingestion of asbestos with food seemed to cause malignant tumors in the gastbos intestinal tract, ${ }^{17-19}$ display several technical inace racies and have been subjected to much criticism (sectien for instance, $\operatorname{Smith}^{20}$ ).

When evaluating the results of experiments on the induction of stomach cancer with asbestos ingesteco with food or water it is necessary to take into accoun尺 that negative results do not rule out the possible role्s of asbestos in the aetiology of stomach cancer, since the conditions of exposure of the stomach wall to asbestos differ greatly from the conditions of con? tinuous stomach exposure to asbestos after its clearo ance by the respiratory escalator mechanism after 3 inhalation. ${ }^{21} 22$ In fact, when asbestos is ingested witlo food its contact time with the stomach wall is limited. by the time the food stays in the stomach, which does not exceed two to three hours. By contrast, dust clear ance from the lungs comes continuously into the mouth and this process ensures that the dust is in continous contact with the stomach wall.

To solve the problem of the role of asbestos in the aetiology of stomach cancer a technique is needed to ensure continuous contact of the stomach wall witts asbestos. This condition is met to a considerable् extent when a perforated plastic capsule containing the substance under study is introduced into the stomach. Continous contact of the suspected carcino $\frac{\sigma}{\infty}$ gen with the stomach wall is ensured by its supple? through the capsule perforations. Different variantso of the capsule method have been used for the 682 
induction of stomach cancer with radiation ${ }^{23}$ or various carcinogens. ${ }^{24-26}$

In our experiment use was made of Arkhipov's technique ${ }^{26}$ to provide direct and continuous contact of the stomach wall with asbestos supplied from the perforated capsule. The capsule was placed into an artificially formed bag in the stomach wall ("small stomach").

\section{Material and methods}

Random bred white rats bred in the nursery of the Academy of Medical Sciences of the USSR were used. The 2-3 month old rats were narcotised by ether and the skin on the abdomen was cut at a distance of $1 \mathrm{~cm}$ from the midline. After opening the abdominal cavity the stomach was brought out through the incision and a $1 \mathrm{~cm}$ long cut was made on the forestomach. Through the cut a capsule containing asbestos mixed with filler (experimental group) or filler alone (control animals) was introduced. An artificial bag (small stomach) was formed around the capsule. The pocket was fastened with a soft wire clip to keep the capsule inside the bag and to ensure continuous contact of its contents with the stomach wall (see fig 1 for operation design). The correct shape of the clip selected allowed traumatisation of the tissue to be reduced. After the formation of the small stomach the wound was sutured in accordance with the normal rules of surgery.

The capsules used $(7-9 \mathrm{~mm}$ in diameter) were blown from heated polyethylene tubes. Perforations were made with a hot needle diameter $0.5 \mathrm{~mm} ; 20-26$ perforations were made, close to the maximum possible. Each capsule was filled with $100 \mathrm{mg}$ chrysotile asbestos mixed with filler through the inlet opening. After a series of preliminary experiments beef fat and natural wax mixture (1:1) with a moderate density at the rat's body temperature was selected as the filler.

After the postoperative period the animals were observed throughout their life. When performing morphological identification of tumours the classification and histological criteria of Nagayo ${ }^{27}$ were used.

\section{Results}

As mentioned above, different variants of the capsule method have been used for modelling contact with the stomach wall of suspected carcinogen by several authors. Our experiment, however, required a series of preliminary experiments to determine the optimal filler; in a separate series of experiments we attempted to find out whether the capsule was indispensable, especially as some experiments have examined the possible carcinogenicity of some plastic materials.

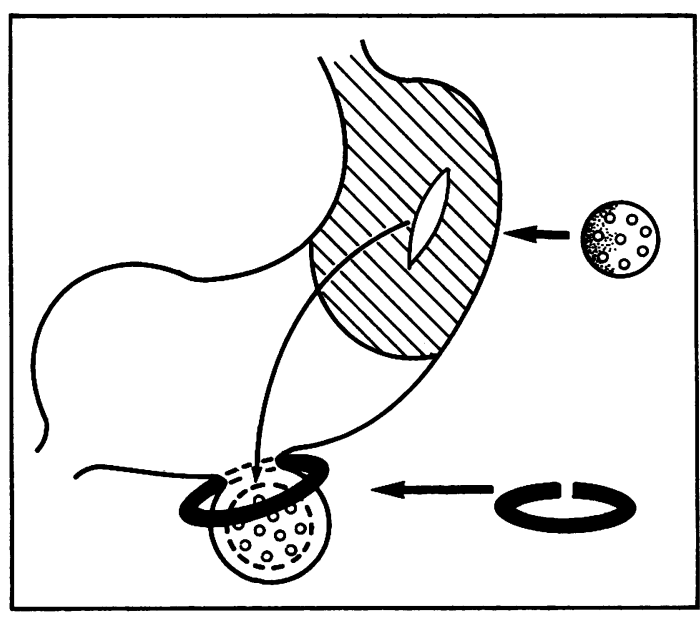

Fig 1 The operative design.

When asbestos and filler pills were used instead of capsules even pills from natural wax having the highest melting point (at a rat's body temperature) remained in the stomach for only three months in a third of the cases, whereas the mass of the pills was reduced to a quarter of the initial value. ${ }^{28}$ Capsules ensured that the asbestos remained in contact with the mucous membrane of the stomach wall until the end of the experiment, when at least a quarter of the initial amount of dust remained in the capsule.

The operation described is rather traumatic and many rats died soon after the operation.

When analysing local changes (within the surgical field) it should be noted that all the animals, both experimental and control, had pronounced changes in the abdominal cavity. Adhesions, an increase in stomach size, and, in some animals, external signs of gastric dyskinesia - that is, congestion of food and flatulence-were observed. Opening the stomach cavity showed pronounced hyperplasia of the serous and muscular layers, erosions of the stomach wall, atrophic and hypertrophic gastritis, and, in some cases, ulceration, It is possible to connect such histological changes, which were described many times in clinical and experimental surgical operations on the stomach, with the operatve procedure.

The induction of tumours was studied in two separate series of experiments. In the first the surviving animals were killed at month 17 . In this series only benign tumours of the glandular stomach and one malignant tumour of the adjacent tissue were found. These results have been published elsewhere. ${ }^{29}$ The table presents these results in comparison with the results of the second series of experiments.

In the second series of experiments the animals 

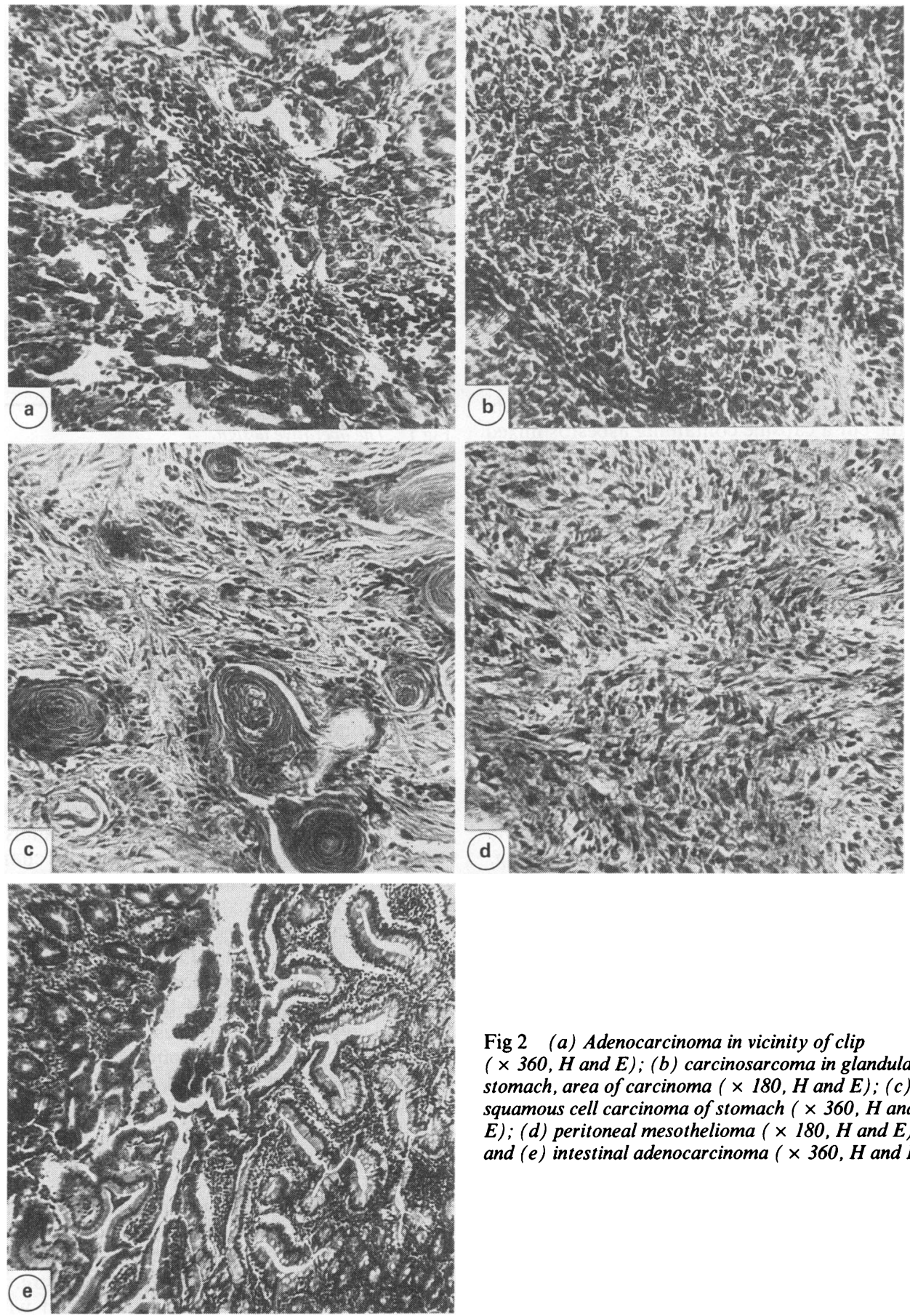

Fig 2 (a) Adenocarcinoma in vicinity of clip $(\times 360, H$ and $E) ;(b)$ carcinosarcoma in glandular stomach, area of carcinoma $(\times 180, H$ and $E) ;(c)$ squamous cell carcinoma of stomach $(\times 360, H$ and $E) ;(d)$ peritoneal mesothelioma $(\times 180, H$ and $E)$; and $(e)$ intestinal adenocarcinoma $(\times 360, H$ and $E)$. 
Table Classification of tumours in the abdominal cavity of rats exposed to asbestos administered into the small stomach

Types of tumours

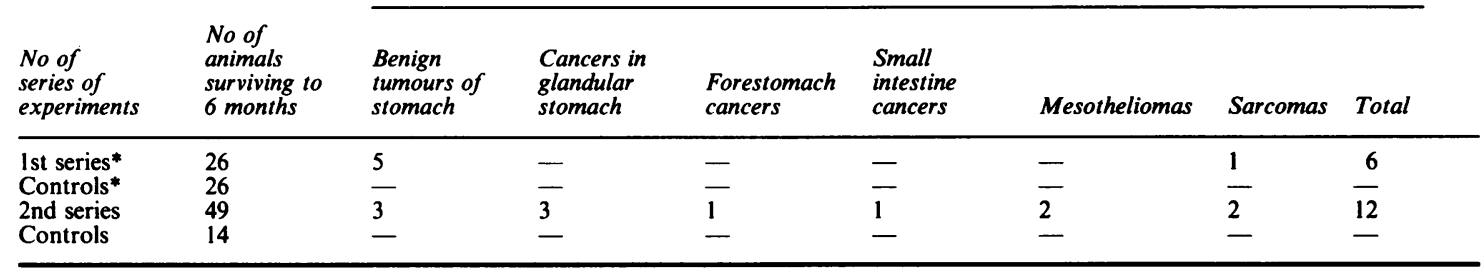

*From Blokhin and Kogan. ${ }^{29}$

were observed throughout their life. In several cases rats which survived to 2.5 years were killed. Both benign and malignant tumours were observed in these experiments (table).

In the glandular part of the stomach within the zone of the small stomach three malignant tumours were found - two adenocarcinomas and one carcinosarcoma (figs $2 a$ and $b$ ). Compared with analogous tumours in man, these tumours displayed a lower degree of anaplasia and poor infiltration. One rat with adenocarcinoma of the stomach had a metastasis in the liver. One case of squamous cell carcinoma of the stomach originating, most probably, in the forestomach was observed (2c).

It is important to note also the development of two peritoneal mesotheliomas in the vicinity of the clip separating the small stomach from the main part of the stomach. The tumours were $3 \times 2.5 \times 1.5 \mathrm{~cm}$ and $3 \times 3 \times 2 \mathrm{~cm}$, respectively. Histologically they were mesotheliomas with sarcoma like cells (fig 2d).

In addition to the stomach tumours and mesotheliomas, three more malignant tumours were found-one adenocarcinoma of the small intestine and two fibrosarcomas in the vicinity of the clip (fig 2e).

Thus the histological investigation of 75 rats showed a total of 18 tumours of the stomach and abdominal cavity, of which eight were benign and 10 malignant. These tumours were observed between $1 \cdot 5$ and 2.5 years after the beginning of the experiment; no such tumours were observed in the control rats.

We have not observed any differences between control and experimental groups in the number or histological type of tumours in other organs and tissues.

\section{Discussion}

When interpreting the data obtained in these experiments it is necessary to take into account that the rate of spontaneous tumours of the stomach and specifically of the glandular stomach in rats is low, ${ }^{2730-32}$ ranging from none to estimates as low as hundredths or even thousandths of a per cent. $^{2730-32}$ The fact that in $24 \%$ of the animals in our experiment tumours developed in the abdominal cavity raises the possibility that they were caused by asbestos. The possible carcinogenic effect of adhesions, the suture materials in the abdominal cavity, and the polyethylene coating of the clip cannot be ruled out. The intraperitoneal administration of polyethylene films has resulted, in some cases, in malignancies developing in the abdominal cavity ${ }^{33-35}$

Surgical intervention is connected with traumatisation of the stomach wall. The traumatic factors are the clip, forming the small stomach, and the plastic capsule with its roughness caused by the perforations made in it. The incidence of tumours in the stomach after surgical operation in man amounts to $6 \% .^{36}$ To account for the possible effect of these factors, analogous operative manipulations were performed on 40 control rats and no tumours were found in this group. Thus there are grounds to consider that the tumours in the stomach and the adjacent part of the abdominal cavity were induced by asbestos. This is supported by two mesotheliomas-serous-found in the experimental group that are characteristic of exposure to asbestos.

We are far from drawing practical conclusions based on the data of this experiment alone. At the same time, the results of this investigation support data we have obtained from several epidemiological investigations: malignant tumours of the stomach together with bronchogenic cancer of the lung and mesothelioma of the pleura and the peritoneum may be caused by continuous exposure to asbestos containing dust. This concept is in accord with the suggestion of a systemic or multipotential carcinogenic potential of asbestos (see, for example, Goldsmith ${ }^{37}$ ).

We much appreciate the help of Dr N I Sherenesheva (All-Union Oncological Research Centre, Moscow) and Dr N N Vlasov (Research Oncological Institute, Leningrad) for generous advice in the histological interpretation of our results.

\section{References}

1 Selikoff IJ. Epidemiology of gastrointestinal cancer. Environ Health Perspect 1974;9:299-305. 
2 Miller AB. Asbestos fibre dust and gastro-intestinal malignancies. Review of literature with regard to a cause/effect relationship. J Chronic Dis 1978;31:23-33.

3 Hiller U, Lange H, Rämsch R, Hiller M. Maligne Tumoren des Gastrointestinaltraktes bei Patienten mit asbestinduzierter Pleurahyalinose. Deutsche Gesundheitswesen 1983;38:1098-102.

4 Tait N. Further reasons why the asbestos problem remains unresolved. Health and Safety at Work 1984;6:76-8.

5 Conforti PM, Kanarek MS, Jackson AJ, Cooper RC, Marchio JC. Asbestos in drinking water and cancer in the San Francisco bay area. J Chronic Dis 1981;34:211-24.

6 Nicholson WJ. Human cancer risk from ingested asbestos: a problem of uncertainty. Environ Health Perspect 1983; 53:111-3.

7 Kogan FM, Guselnicova NA. Current state and perspectives of studying the malignant tumour's problems in the asbestos industry in the USSR. In: Domnin SG, Katsnelson BA, eds. Occupational diseases of dust aetiology. Moscow: Erisman Institute of Hygiene, 1981:24-9.*

8 Webster I. The ingestion of asbestos fibres. Environ Health Perspect 1974;9:199-202.

9 Gross P, Harley RA, Swinborne LA, Davis J, Greene WB. Ingested mineral fibers: do they penetrate tissue or cause cancer? Arch Environ Health 1974;29:341-7.

10 Smith WE, Hubert DD, Sobel HJ, Peters ET, Doerfler TE. Health of experimental animals drinking water and without amosite asbestos and other mineral particles. J Environ Pathol Toxicol Oncol 1980;3:277-300.

11 Douharn KI, Berg EW, Will LA, Leininger JK. The effects of long-term ingestion of asbestos on the colon of F 344 rats. Cancer 1980;45:1073-84.

12 Hilding AC, Hilding DA, Larson DM, Aufderheide AC. Biological effects of ingested amosite asbestos, taconite tailings, diatomaceous earth and Lake Superior water in rats. Arch Environ Health 1981;36:298-303.

13 Bolton RE, Davis JMG, Lamb D. The pathological effects of prolonged asbestos ingestion in rats. Environ Res 1982;2: 134-50.

14 National Toxicology Program. Technical report on the lifetime carcinogenesis studies of amosite asbestos in Syrian golden hamsters (feed studies). Tringle Park, N Carolina: National Institutes of Health, US Department of Health and Human Services Research, 1983.

15 Moore SA. National Institute of Environmental Health and Safety oral asbestos studies. Gaitsberg: National Bureau of Standards, 1977:153-61. (Special publ 506.)

16 Anonymous. Government animal feeding effect of ingested asbestos. A/C Pipe Producers Association Advisory 1981 (July), 1.

17 Cunningham HM, Moodie CA, Lawrence GA, Pontefract RD. Chronic effects of ingested asbestos in rats. Arch Environ Contam Toxicol 1977;6:507-13.

18 Gibel W, Lohs K, Horn K, Wildner GP, Hoffman F. Experimental study of carcinogenic activity of asbestos filters after oral administration. Arch Geschwülstforsch 1976;46:437-42.

19 Ward JM, Frank AL, Wenk M, Devor D, Tarone RE. Ingested asbestos and intestinal carcinogenesis in F 344 rats. $J$ Environ Pathol Toxicol Oncol 1980;3:301-12.
20 Smith WE. Report on summary workshop on ingested asbestos $\overline{\bar{\partial}}$ Meeting arranged by US Environmental Protection Agency in Breidenbach Research Center, Cincinnati, Ohio, report pre- $\vec{D}$ pared for Canadian Asbestos Information Centre, 1982.

21 Watson JA, Spritzer AA, Auld JA, Quetthoff MA. Deposition and clearance following inhalation and intratracheal injections? of particles. Arch Environ Health 1969;19:51-8.

22 Dannenberg AM. Influence of environmental factors on the respiratory tract (summary and perspectives). J Reticulo $\frac{\overline{\mathrm{C}}}{\mathrm{S}}$ endothelial Society 1977;22:273-90.

23 Moore GE, Smith G, Brakney EL. Use of intragastric balloons containing $P^{32}$ in an attempt to produce adenocarcinoma of then stomach in the mouse. JNCI 1953;13:963-77.

24 Arkhipov IN. New effective method for ensuring the long-term $\vec{b}$ contact between carcinogens and glandular stomach wall: Pathological Physiology and Experimental Therapy $\vec{\omega}$ 1968;Apr:73-6.*

25 Majima S, Takahashi T, Narisawa T, Yamaqudei I. Attempt ato experimental production of carcinoma in gastric ulcer. Toxok $\mathbb{D}$ Journal of Experimental Medicine 1966;90:277-90.

26 Volfson NI. On histogenesis of hyperplastic changes in the stomach in mice. Vopr Oncol 1979;25:66-71.*

27 Nagayo T. Tumours of the stomach. In: Pathology of tumours in $\overrightarrow{0}$ laboratory animals. Vol I. Tumours of the rat. Lyon: Inter-O national Agency for Research on Cancer, 1973:101-40. (SciN publ No 5.)

28 Vanchugova NN, Frasch VN, Kogan FM. On the migration of asbestos fibres from "artificial bag" of rat's stomach. In: Domnin SG, Katsnelson BA, eds. Occupational diseases of dus aetiology. Moscow: Erisman Institute of Hygiene, 1982:45-8.

29 Blokhin VA, Kogan FM. Experimental data on the cancerogenid action of some chromium salts and chrysotile-asbestos on the stomach. In: Domnin SG, Katsnelson BA, eds. Occupationat $\overrightarrow{0}$ diseases of dust aetiology. Moscow: Erisman Institute $\infty b_{\infty}$ Hygiene, 1981:43-7.*

30 Streltsova VN, Moskalev JI. Blastomogenic effect of radiationn Moscow Medicin 1964:167-81.*

31 Rowlatt UF. Neoplasms of the alimentary canal of rats and mize. In: Cotchin E, Roe FJC, eds. Pathology of laboratory rats and mice. Oxford: Blackwell, 1967:57-82.

32 Pliss GB, Jogannsen MG, Romanov K. Tumour's pattern of random bred white rats from nursery of Leningrad's Institute of Oncology. Vopr Oncol 1982;28:75-8.*

33 Hueper WC. Cancer induction by polyurethane and polysilicone plastics. JNCI 1964;33:1005-27.

34 Shabad LM. Plastic induced cancerogenesis. In: Rakov IA, ed Actual problems in oncology. Leningrad, 1966:6-12.*

35 Shitkov KT, Talalaeva AW. Sarcomas of rat's stomach induced by DMBA and cellophane. Vopr Oncol 1979;25:62-5.*

36 Esipov BK, Jaglinski BA. On the preneoplastic changes of glandular part in postoperative stomach. In: Kozhevnicova EP, ed. Pathogenesis diagnostics and treatment of malignant neoplasmsKujbishev: Medical Institute, 1984:57-61.*

37 Goldsmith JK. Asbestos as a systemic carcinogen: the evidence? from eleven cohorts. Am J Ind Med 1982;3:341-8.

* In Russian. 